\title{
RESEARCH ON THE MECHANICAL AND Chemical Resistance Of PRINTS
}

\author{
BATES, I.; MiLETIC, M. \& ZJAKIC, I.
}

Abstract: Flexographic printing process is a fast growing printing technique, whereby it became a more competitive printing method in the packaging production. Flexographic printing process is a quality and cost-effective printing technique used for a wide range of substrates such as foils, plastic films, corrugated boards, papers or even fabrics. Nowadays, it is even becoming a strong competition to the gravure printing process in performing more demanding printing. Each good quality printing technique, especially the one which pertains to the packaging, includes prints which must have good adherence to the printing substrate, that is, they must have good coverage of printing substrate with ink. Considering the aim of protecting environment and using inks that are free of VOC evaporation, the inks compared in this paper are the conventional inks, which are solvent based, and they substitute UV inks. The comparison of the mechanical and chemical resistance has been performed based on objective and subjective measurements. The mechanical resistance of the samples was examined by means of scratch and crinkle methods and with rub resistance test while the chemical resitance of the samples was tested with 10 different agents.

Key words: flexographic printing process, solvent based inks, UV inks, mechanical resistance, chemical resistance
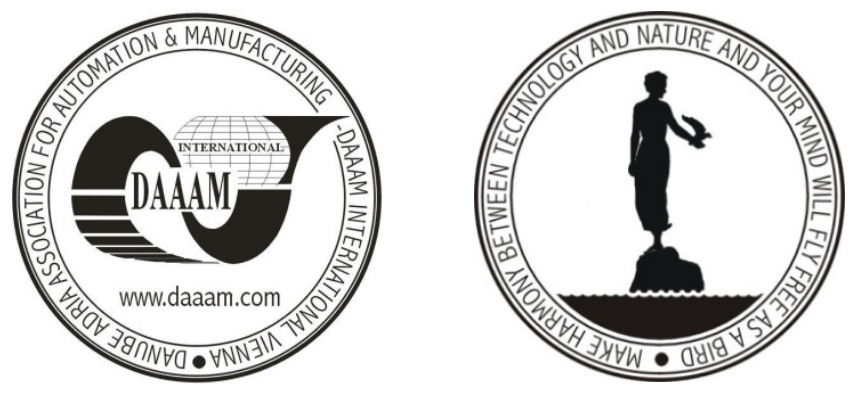

Authors' data: Dipl.-Ing. Bates, I[rena]; Dipl.-Ing. Miletic, M[artina]; Prof. Ass. Dr. Sc. Zjakic, I[gor], University of Graphic Arts, Getaldiceva 2, 10000, Zagreb, Croatia, irena.bates@grf.hr, martina.miletic@gmail.com, zjakic@grf.hr

This Publication has to be referred as: Bates, I[rena]; Miletic, M[artina] \& Zjakic, I[gor] (2009). Research on the Mechanical and Chemical Resistance of Prints, Chapter 55 in DAAAM International Scientific Book 2009, pp. 561-572, B. Katalinic (Ed.), Published by DAAAM International, ISBN 978-3-901509-69-8, ISSN 17269687, Vienna, Austria

DOI: $10.2507 /$ daaam.scibook.2009.55 